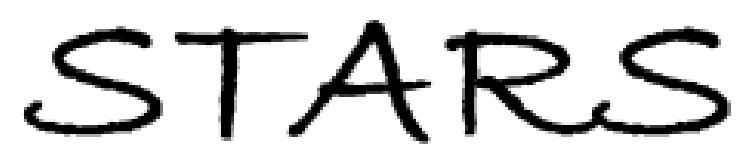

University of Central Florida

STARS

Faculty Bibliography 2000s

Faculty Bibliography

$1-1-2003$

\title{
Curing temperature effects on liquid crystal gels
}

Fang Du

University of Central Florida

Shin-Tson Wu

University of Central Florida

Find similar works at: https://stars.library.ucf.edu/facultybib2000 University of Central Florida Libraries http://library.ucf.edu

This Article is brought to you for free and open access by the Faculty Bibliography at STARS. It has been accepted for inclusion in Faculty Bibliography 2000 s by an authorized administrator of STARS. For more information, please contactSTARS@ucf.edu.

\section{Recommended Citation}

Du, Fang and Wu, Shin-Tson, "Curing temperature effects on liquid crystal gels" (2003). Faculty Bibliography 2000s. 3718.

https://stars.library.ucf.edu/facultybib2000/3718

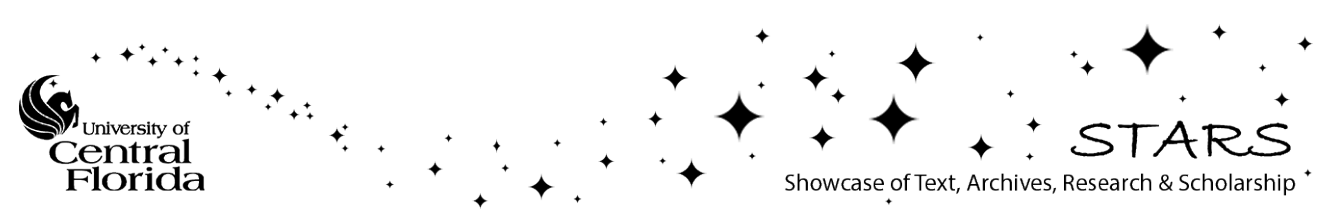




\section{Curing temperature effects on liquid crystal gels}

Cite as: Appl. Phys. Lett. 83, 1310 (2003); https://doi.org/10.1063/1.1602152

Submitted: 28 March 2003 . Accepted: 17 June 2003 . Published Online: 12 August 2003

Fang Du, and Shin-Tson Wu

\section{ARTICLES YOU MAY BE INTERESTED IN}

Cholesteric liquid crystal/polymer dispersion for haze-free light shutters Applied Physics Letters 60, 3102 (1992); https://doi.org/10.1063/1.106765

Fast-switching initially-transparent liquid crystal light shutter with crossed patterned electrodes

AIP Advances 5, 047118 (2015); https://doi.org/10.1063/1.4918277

Fast-response and scattering-free polymer network liquid crystals for infrared light modulators

Applied Physics Letters 84, 1233 (2004); https://doi.org/10.1063/1.1649816

\section{Applied Physics Letters}

Mid-IR and THz frequency combs special collection

\section{Read Now!}




\title{
Curing temperature effects on liquid crystal gels
}

\author{
Fang Du and Shin-Tson $\mathrm{Wu}^{\mathrm{a})}$ \\ School of Optics/CREOL, University of Central Florida, Orlando, Florida 32816
}

(Received 28 March 2003; accepted 17 June 2003)

\begin{abstract}
The curing temperature is found to greatly affect the operating voltage, contrast ratio, hysteresis, and response time of the reversed-mode liquid crystal (LC) gels. For the gels using E48 LC host, the optimal curing temperature is around $40-50^{\circ} \mathrm{C}$. An LC gel with contrast ratio exceeds 2000:1 (at $\sim 2^{\circ}$ collection angle), operating voltage lower than $7 V_{\mathrm{rms}}$, and response time of about $20 \mathrm{~ms}$ is demonstrated. Potential applications of such LC gels for optical switches, displays, and switchable polarizers are emphasized. (C) 2003 American Institute of Physics. [DOI: 10.1063/1.1602152]
\end{abstract}

Liquid crystal (LC) gels ${ }^{1,2}$ (or called polymer-stabilized LC) $)^{3}$ exhibit an anisotropic light scattering behavior and can be used as a variable optical attenuator (VOA) for telecommunication, reflective display, and switchable polarizer for sensor protection. ${ }^{4}$ Different from polymer dispersed liquid crystals $^{5}$ in which polymer matrix is optically isotropic, the LC gels are optically anisotropic. Both reversed and normal mode gels have been developed. In a reversed-mode LC gel, a low concentration $(<10 \%)$ of diacrylate monomer is dissolved in an LC host and then injected to an empty cell with homogeneous alignment. A weak UV light is used to induce photopolymerization. In the voltage-off state, the polymer networks and LC molecules have the same orientation and thus the cell is highly transparent. With applied voltage, the polymer networks resist LC directors from being reoriented by the electric field. As a result, microdomains are formed and threshold voltage increased. The light polarization parallel to the rubbing direction is scattered and the orthogonal polarization is transmitted. On the other hand, the normalmode gel is polymerized with a bias voltage. ${ }^{6}$ It scatters light in the voltage-off state and transmits light in the voltage-on state.

The major shortcomings of the LC gels are inadequate contrast ratio, relatively high operating voltage, and noticeable hysteresis. For active matrix addressed flat panel displays, the maximum operating voltage should be lower than $7 V_{\text {rms }}$. To improve contrast ratio, one could use a thicker cell gap. The tradeoff is that both driving voltage and hysteresis are increased. There is an urgent need to develop methods for enhancing contrast ratio, reducing operating voltage, and suppressing hysteresis.

In this letter, we report a two-stage elevated temperature curing process that leads to a high contrast ratio, low operating voltage, and small hysteresis. By controlling the curing temperature and LC/polymer composition properly, we have demonstrated a transmissive reversed-mode LC gel with contrast ratio over 2000:1 and operating voltage as low as $\sim 0.87$ $\mathrm{V} / \mu \mathrm{m}$. These results are at least one order of magnitude better than the previously published data. ${ }^{1,4}$

To fabricate LC gels, we mixed a few percent of bisphenol A dimethacrylate monomer in a Merck E48 LC mixture $(\Delta n=0.23$ at $\lambda=589 \mathrm{~nm})$. The LC/monomer mixture was

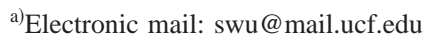

injected into an empty cell with homogeneous alignment. The pretilt angle of the buffed polyimide alignment layers is about $3^{\circ}$. The sample cell was then exposed to a weak UV light $\left(100 \mu \mathrm{W} / \mathrm{cm}^{2}\right)$ to induce polymerization. Being influenced by the surface rubbing effect, the polymer networks basically follow the same LC alignment direction. In our two-stage curing process, for the first half an hour the cell was kept at an elevated temperature during UV exposure. In fact, this procedure would slow down the polymerization rate $^{7}$ and create larger dispersion of polymer and LC. ${ }^{8}$ The coarser polymer networks produce larger microdomain sizes in the voltage-on state. As a result, the dark (light scattering) state voltage is reduced. After the first $30 \mathrm{~min}$ of UV exposure at elevated temperature, the sample was moved away from heating stage and left at room temperature. The UV exposure continued for another $5.5 \mathrm{~h}$ at room temperature to further stabilize the polymer network. We have studied the curing temperature effect from room temperature to $70{ }^{\circ} \mathrm{C}$.

To characterize the gels performance, we measured the voltage-dependent transmittance using a linearly polarized $\mathrm{He}-\mathrm{Ne}$ laser beam. A wide dynamic range photodiode detector (with $1 \mathrm{~cm}$ diameter) was set at $30 \mathrm{~cm}$ from the sample holder (equivalent to $\sim 2^{\circ}$ collection angle). The laser polarization axis is parallel to the LC cell's rubbing direction. The voltage-dependent light transmission was recorded by a computer-controlled LabVIEW system. During our experiments, we measured normalized transmittance. All the optical losses from substrate reflections were neglected. In the voltage-off state, the sample is highly transparent. When the applied voltage is increased, the laser beam is scattered by the micron-sized domains and the gel acts as a linear polarizer.

Figure 1 plots the normalized transmittance of the $8 \mu \mathrm{m}$ LC gels prepared at different curing temperatures (from right to left: $23,32,50$, and $70^{\circ} \mathrm{C}$ ). As the curing temperature was increased from 23 to $70^{\circ} \mathrm{C}$, the dark state voltage was reduced linearly from 11.9 to $5.5 V_{\text {rms }}$. The high temperature curing process slows down the polymerization rate and produces coarser polymer networks. As a result, the electric field induced domain sizes are larger which, in turn, reduces the dark state voltage. Such a low operating voltage enables the LC gels to be addressed by the amorphous silicon thin-filmtransistors for display or two-dimensional VOA array applications. 


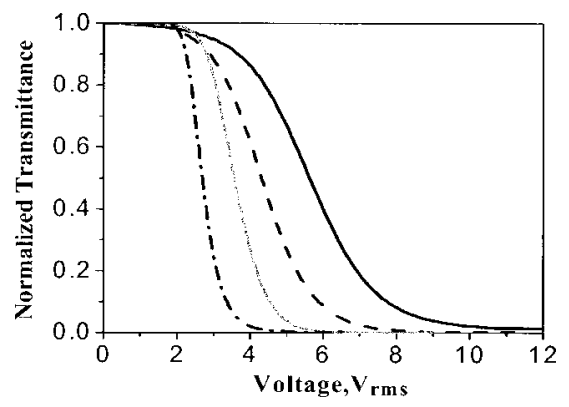

FIG. 1. The voltage-dependent transmittance of the E48 LC gels at 23, 32, 50 , and $70^{\circ} \mathrm{C}$ curing temperatures (from right to left). Cell gap $d=8 \mu \mathrm{m}$, monomer concentration $4 \mathrm{wt} \%$, laser wavelength $\lambda=633 \mathrm{~nm}$, and measurement temperature $T=23{ }^{\circ} \mathrm{C}$.

From Fig. 1, the dark state transmittance is strongly affected by the curing temperature. Figure 2 shows the curing temperature-dependent maximum contrast ratio of the $8 \mu \mathrm{m}$ E48 LC gels with $4 \%$ monomer concentration. For the case of room temperature curing, the maximum contrast ratio is $\sim 70$ for the $8 \mu \mathrm{m} \mathrm{LC}$ gel. This result is consistent to that reported in Ref. 4. As the curing temperature is increased to $\sim 50{ }^{\circ} \mathrm{C}$, the contrast ratio reaches $2000: 1$ and the dark state voltage remains lower than $7 V_{\text {rms }}$. The contrast ratio is improved by $\sim 30 \times$. It is commonly known that the contrast ratio of a light scattering device is greatly dependent on the collection angle. As the collection angle increases from $2^{\circ}$ to $6^{\circ}$, our measured contrast ratio drops by $5 \times$. In fiber-optic communications, the collection angle is usually less than $2^{\circ}$. As the curing temperature continues to increase, the domain size becomes too big in comparison to the laser wavelength. Although the dark state voltage is further reduced, the light scattering capability is weakened which results in a lower contrast ratio.

We also studied the curing temperature effect on hysteresis and response time. The measured results are depicted in Figs. 3 and 4 , respectively. The hysteresis width $\delta V$ is defined as $V_{\text {down }}-V_{\text {up }}$ where $V_{\text {down }}$ and $V_{\text {up }}$ are the voltages corresponding to $50 \%$ transmittance for the forward and reverse voltage scans. From Fig. 3, the hysteresis width is suppressed by nearly $3 \times$ as the curing temperature increases from 23 to $70{ }^{\circ} \mathrm{C}$. For optical switch applications, the major performance criteria are high extinction ratio, low voltage, and fast response time; hysteresis is not a big concern. However, for gray scale display and VOA devices, hysteresis is undesirable and should be minimized.

Although high temperature curing lowers the dark state

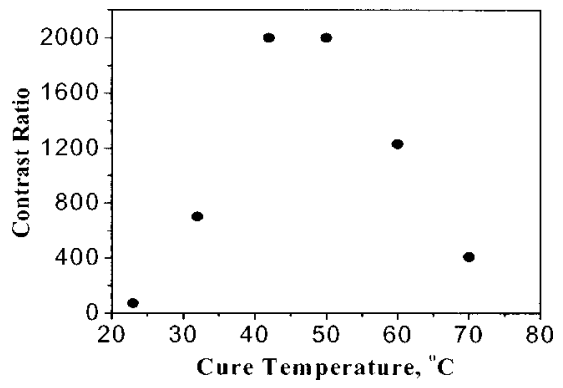

FIG. 2. The curing temperature dependent contrast ratio of the E48 LC gels containing $4 \%$ monomer concentration. Cell gap $d=8 \mu \mathrm{m}, \lambda=633 \mathrm{~nm}$, and $T=23^{\circ} \mathrm{C}$.

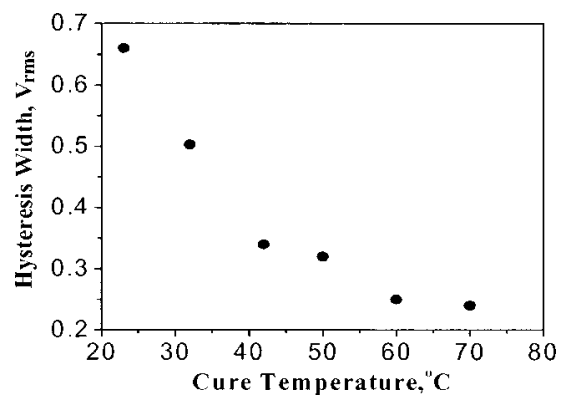

FIG. 3. The curing temperature dependent hysteresis of the E48 LC gels containing $4 \%$ monomer concentration. Cell gap $d=8 \mu \mathrm{m}, \lambda=633 \mathrm{~nm}$, and $T=23{ }^{\circ} \mathrm{C}$.

voltage, enhances the contrast ratio and suppresses the hysteresis width, it has a drawback in slower response time. Figure 4 shows the measured rise and decay time of the 8 $\mu \mathrm{m}$ and $4 \mathrm{wt} \% \mathrm{E} 48 \mathrm{LC}$ gels at various curing temperatures. Both turn-on and turn-off times increase with the increased curing temperature. In general, the response time of a LC gel is affected by the LC viscosity, cell gap, and microdomain sizes. Benefiting from the driving voltage effect, the rise time shown in Fig. 4 is faster than the decay time. The slower decay time in the higher curing temperature implies that the network is coarser. This is consistent with the lower dark state voltage observed for the higher curing temperature, as shown in Fig. 1.

To improve response time, we chose to use a thinner cell gap as an example. For a $5 \mu \mathrm{m}$ E48 LC gel cured at $T$ $=50^{\circ} \mathrm{C}$, its rise and decay times were measured to be 6.4 and $11.8 \mathrm{~ms}$, respectively, and the contrast ratio at $4.5 V_{\text {rms }}$ was 1000:1. The reason that we do not see improvement on the rise time of the $5 \mu \mathrm{m}$ gel is due to its lower dark state voltage. The rise time of an LC device is dependent on the ratio of the on-state voltage over the threshold. ${ }^{9}$

Monomer concentration is another important factor affecting the gel performance. From Fig. 2, the optimal curing temperature for the E48 gels occurs at $T \sim 40-50{ }^{\circ} \mathrm{C}$. Thus, we prepared five samples with 2, 3, 4, 5, and $6 \mathrm{wt} \%$ monomer concentrations at $50^{\circ} \mathrm{C}$ curing temperature. The cell gap is $8 \mu \mathrm{m}$. Results are shown in Fig. 5. From Fig. 5, the dark state voltage increases from 5.5 to $9.5 V_{\text {rms }}$ as the monomer concentration increases from $2 \%$ to $6 \%$. The increased threshold and dark state voltages for a higher polymer concentration originates from the smaller domain sizes. For the $2 \%-4 \%$ gels, the device contrast ratio remains as high as

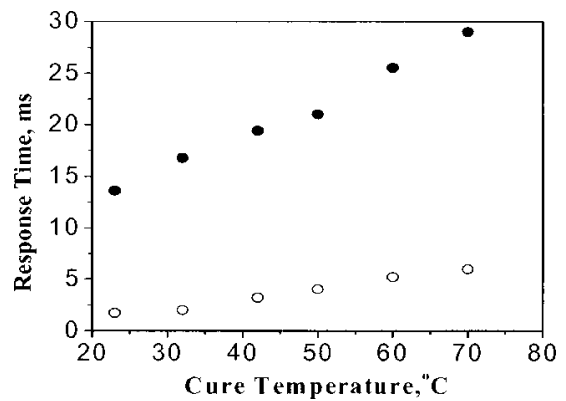

FIG. 4. The curing temperature dependent rise time (open circles) and decay time (close circles) of the $8 \mu \mathrm{m}$ E48 LC gels with $4 \%$ monomer concentration. For each cell, the rise and decay times were measured between $V=0$ and the corresponding dark state voltage shown in Fig. 1. 


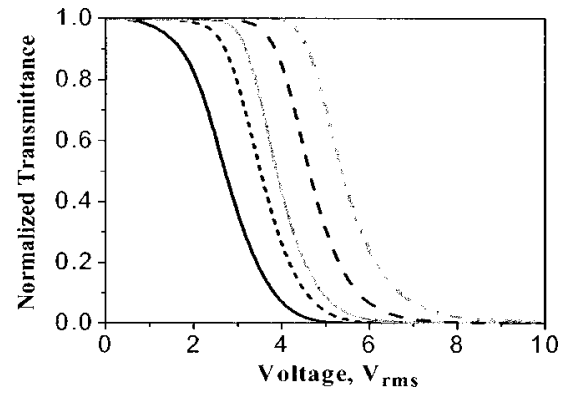

FIG. 5. The voltage-dependent transmittance of E48 LC gels with 2, 3, 4, 5, and $6 \mathrm{wt} \%$ (from left to right) monomer concentrations. The first-stage sample curing temperature is $50^{\circ} \mathrm{C}$. LC cell gap $d=8 \mu \mathrm{m}$, operating temperature $T=23^{\circ} \mathrm{C}$, and $\lambda=633 \mathrm{~nm}$.

2000:1, but drops rapidly to $170: 1$ as the monomer concentration increases to $6 \%$. In a high monomer concentration LC gel, the domain sizes are too small to effectively scatter the $\mathrm{He}-\mathrm{Ne}$ laser light.

We also measured the light scattering loss for the laser polarization which is orthogonal to the cell rubbing direction. The loss was less than 5\%, similar to that reported in Ref. 4. This indicates that the gel's light scattering behavior is indeed very anisotropic. The turn-on and -off times for the $3 \%$, $4 \%, 5 \%$, and $6 \%$ gels were measured to be $(6,26),(4,21)$, $(3,12)$, and $(2,8) \mathrm{ms}$, respectively.
In conclusion, we have developed a two-stage elevated temperature curing method for achieving LC gels with high contrast ratio, low operating voltage, small hysteresis, and reasonably fast response time. These LC gels will find useful applications in variable optical attenuators for telecom, transmissive and reflective displays, and scattering polarizer for sensor protection.

The authors are indebted to Dr. Hongwen Ren for his technical assistances and discussions. This work is supported by AFOSR under Contract No. F49620-01-1-0377.

${ }^{1}$ R. A. M. Hikmet and H. J. Boots, Phys. Rev. E 51, 5824 (1995).

${ }^{2}$ R. A. M. Hikmet, J. Appl. Phys. 68, 4406 (1990).

${ }^{3}$ R. Q. Ma and D. K. Yang, Phys. Rev. E 61, 1567 (2000).

${ }^{4}$ H. Ren and S. T. Wu, Appl. Phys. Lett. 81, 1432 (2002).

${ }^{5}$ J. W. Doane, N. A. Vaz, B. G. Wu, and S. Zumer, Appl. Phys. Lett. 48, 269 (1986).

${ }^{6}$ Y. H. Fan, H. W. Ren, and S. T. Wu, Appl. Phys. Lett. 82, 2945 (2003).

${ }^{7}$ T. Murashige, H. Fujikake, S. Ikehata, and F. Sato, Jpn. J. Appl. Phys., Part 2 41, L1152 (2002).

${ }^{8}$ I. Dierking, L. L. Kosbar, A. C. Lowe, and G. A. Held, Liq. Cryst. 24, 387 (1998).

${ }^{9}$ S. T. Wu and D. K. Yang, Reflective Liquid Crystal Displays (Wiley, New York, 2001). 